\title{
Criminal Protection of Wild Animals under Perspective of Biodiversity Protection
}

\author{
Wenjie Li \\ Inner Mongolia University for the Nationalities, Tongliao, 028000, China
}

Keywords: Biodiversity; Wild animals; Criminal protection

\begin{abstract}
Biodiversity protection is actually a legal system. Criminal protection of wild animals is a very important content. Criminal protection of wild animals has been done well in developed countries. With social development, China also starts to pay attention to criminal protection of wild animals. Although certain achievements have been achieved for criminal protection of wild animals under the perspective of biodiversity protection, some problems and shortcomings also exist. Thus, we need to continuously enhance criminal protection force, establish rational criminal law system, and promote development of wild animals. This paper mainly studies criminal protection of wild animals under biodiversity protection system and the problems, and puts forward reasonable improvement measures.
\end{abstract}

\section{Introduction}

Biodiversity is actually the sum of all kinds of processes related to environment and biology, mainly including ecological system consisting of plants, animals, microorganism as well as their living environment and genes. An important part of ecological system and biodiversity is wild animal production. Rational wild animal production has important significance for ecological balance, species diversity protection social and economic development as well as quality and civilization. Therefore, we must do well criminal protection of wild animals under the perspective of biodiversity protection.

\section{Biodiversity protection is legal system}

Biodiversity is a type of biology subject and topic of natural science. Hence, biodiversity protection is actually a legal system. For the whole world, desertification and sharp decrease in forest vegetation in developing countries cause that animals and plants gradually die out. The extinction speed is also on the rise. Gradual decrease in rare species becomes major environmental problem in the whole world. So, biodiversity protection gradually receives attention and is included in public international law. Biodiversity protection is a legal system to protect plants, animals and microorganisms as per laws and also a behavior of state, government, society and human, mainly including the following aspects:

\section{Protection of animals, plants and microorganisms}

Biodiversity protection is actually protection of plants, animals and microorganisms, especially diversity of rare species of animals and plants and genetic diversity. Species diversity mainly includes species formation, status, continuity, maintenance, extinction speed and endangering degree. Protection of species diversity actually refers to rational and effective utilization and protection by use of laws, regulations, science and technology. Genetic diversity to some extent influences whether species can continue and survive. Genetic diversity protection means to continuously analyze gene change rule and adopt effective methods to protect gene inheritance and variation so as to facilitate species development and proliferation. 


\section{Protection of ecological system}

Protection of ecological system mainly aims to protect ecological environment, ecological functions and functions of ecological community. Meanwhile, it is an important content of biodiversity protection. Continuous change in ecological system will gradually trigger changes in animals and plants. For example, reduction of forest vegetation will cause animals and plants are in imminent danger and disappear until they perish. Frequent afforestation will form the landscape where green trees generate shade and many birds contend in singing.

\section{Landscape protection}

In fact, landscape is the space unit of the earth's surface and the product of human and environment appearing on the earth's surface in terms of time and space, mainly including vegetation, topography and land etc. After continuous combination, finally special shape forms. Landscape protection can promote tourism development to some extent, alter human living environment and improve living quality. Landscape protection has far-reaching significance for nature protection and tourism development.

\section{Important position of wild animal protection in biodiversity protection}

\section{Important relationship between wild animals and human}

Wild animal are human valuable resources and also irreplaceable constituent part in natural ecological system. Meanwhile, it is also the root of biodiversity. In the whole natural ecological system, the function of each wild animal cannot be replaced and lost. To protect all human beings, wild animals must be protected. Human is an important component of top food chain. If wild animals disappear, human life activities will be affected. So, protection of wild animals is widely accepted by human. China has a vast territory. Natural environment is diversified and complex. Wild animal resources are very rich. China is one of the countries with the most wild animals. The proportion of species accounts for more than $10 \%$ of total quantity of wild animals. If these species decrease or disappear, natural economy will lose balance, and human will encounter great calamity. In fact, in human evolution process, wild animals make great contributions. In early primitive society, human ancestors were unable to plant crops and raise livestock, so they could only maintain physical agility by depending on primitive stone, wood, bow and arrow and eating wild animals. They wore fur and feather of animals to get warm for survival and development. Even today when science and technology are very developed, wild animals become important sources for human to gain fur, protein, rare medicines and grease. In painting, musical creation and literature works, wild animals serve as inspiration object or depiction object. Wild animals also make great contributions to agriculture and forestry as well as medicine. For example, birds are natural enemies of injurious insects and bandicoots. Coccinella septempunctata can remove aphid. They are the bodyguards to protect agriculture and forestry. Thus, wild animals play a decisive role in maintaining ecological balance. Biodiversity protection is closely related to human.

\section{Urgency and arduousness of wild animal protection}

Protection of wild animal resources is an arduous and urgent. The earth is the cradle of breeding life and also the common home of wild animals and human. So, human and animals should coexist harmoniously. We should jointly protect ecological balance. But, as world population is on the rise, and science and technology become increasingly developed, environment becomes more and more deteriorated. Besides, air and water pollution is serious. Acid rain destroys forest vegetation, and global climate gradually becomes warm. In addition, human increases acquisition of wild animal resources. Wild animal habitat is also destroyed. Wild animal resources are gradually exhausted. Their future survival suffers unprecedented threat. According to the data, since 1700, about 110 kinds of birds and more than 160 kinds of animals have died out. The survey results show the extinction speed of wild species caused by human factors is 1000 times of natural extinction speed. Scientists 
predict that biology on the earth will become extinct in 30 years. Nowadays, human has realized the danger. Before the value is known, wild animals have disappeared. Scientists have proposes warning that if people still do not change the view and slow down consumption and plunder of nature, wild animals will die and disappear. Besides, crops and farmland will gradually worsen.

At present, the whole world is faced with extinction of wild species. Wild animal protection has been included in state-owned laws and rules. First offenders will be punished criminally. In other words, each country has discovered species extinction gives rise to great threat to human. So, biodiversity protection is the priority among priorities, because protection of wild animals means protection of ourselves.

\section{China's criminal law for wild animal protection has defects}

\section{Protection range is narrow}

Since there is sufficient consciousness of biodiversity protection, during formulating criminal law of wild animal protection, many legislations are made only in allusion to endangered and rare species which are beneficial to economic development and own scientific research. Besides, objects of crime damaging wild animals are partially limited to endangered and rare species. Although criminal law of wild animal protection enlarges animal protection scope to some extent, compared with domesticated and captured animals in foreign criminal law, specific, rare and endangered species in China's criminal law seem very narrow.

\section{Legislation is simple and auxiliary criminal law does not comply with articles of criminal law seriously}

Compared with foreign criminal law legislation, China's penal provisions about damages to wild animal resources are relatively simple and blank for poaching and fishing. Whether some behaviors form a crime? China has to refer to other regulations. Criminal law about wild animal protection basically adopts simple charges in an indictment. This brings difficulties to actual operation. Although the criminal law was modified many times, new protection regulations are not launched for wild animal protection. Thus, criminal law inconformity appears. Inharmonious laws and regulations impose serious effects on protection of wild animal resources so that it is hard to reach the due effect.

\section{Deficiency in punishment}

China pays attention to severe blow in terms of criminal penalty. China has severe punishment. Criminal penalty aims to prevent criminal behaviors. Thus, China's criminal penalty inclines to severe punishment to curb crimes through excessive rendering of the threats. Wild animal resource protection is also the case. Generally, China punishes seriously for those damaging wild animal resources, such as illegal hunting, skilling rare animals, transporting and transacting endangered animals and the products. More than 10-year fixed-term imprisonment will be punished and all properties will be confiscated, as appropriate. For those seriously smuggling rare animals, they will be sentenced to life imprisonment or death penalty, and all properties will be confiscated. Pure emphasis of emphasize seriousness and ignorance of ecological balance maintenance and repair are harmful to biodiversity protection. Furthermore, the lack of special defense function gradually becomes the defect in criminal law.

\section{Measures to perfect criminal law for Chinese wild animal resource protection}

\section{To expand criminal law scope of wild animal protection}

According to ecological theory, every kind of species has its existence value and exists in ecological system. The quantity and type of specifies are ever-changing. This will impose certain impacts on ecological environment and ecological stability. Therefore, we must see clearly wild animal protection awareness. We not just need to maintain ecological system balance, but also need 
to keep social economic value so as to solve criminal protection of wild animals. If relatively traditional idea serves as the guiding thought of criminal protection and pushes specifies to poor economy, human will be ultimately punished. In terms of biodiversity protection, China continuously absorbs foreign experience, expands criminal protection range and enhances protection of domesticated and captured animals. Based on animal protection, endangered animals can be confirmed in accordance with the quantity of different species and living area. If they comply, they will be listed in the protection scope.

\section{To perfect law-making stipulations of wild animal resource crime}

Firstly, detailed description of charges in an indictment is adopted as needed. Specific enumeration of crimes of wild animal resource damage makes the provision more operable. Secondly, auxiliary criminal law articles are rationally modified to make criminal them connected with criminal law. For example, Wild Animal Conservation Law is applicable to criminal code in 1979. Similarly, it is also applicable to the articles about punishing criminals catching and killing wild animals in imminent danger which hare mainly protected by the state. Besides, it is necessary to add criminal liability articles as per the provisions about damages to wild animal resources. If other laws and regulations do not coordinate well with criminal law, corresponding modifications should be made.

\section{To perfect criminal penalty for damages to wild animal resource}

The basic target of governing environment crime is not to frighten. It is required to correct people's social concept and people's view on environmental crime. The crime of damages to wild animals is actually destruction of ecological environment and damage to development for the sake of economic benefit. The perniciousness is much smaller than that of traditional crime mode. But, we should implement strict punishment to fully give play to the deterrent force and preventive function of criminal law. Once the damage is caused, it cannot be repaired in a short time. Hence, it is necessary to continuously adapt new trend of criminal law, continuously modify criminal liability for wild animal crimes, attach importance to prevention of crimes from pure punishment of crimes and fully consider resource repair and recovery. Therefore, it is necessary to continuously perfect criminal punishment regulations.

\section{Conclusions}

In conclusion, the benefit of protection of biodiversity and wild animals can be seen in current stage, but the effect has benefits for society, policy and group in the future. We not just need national policy and legal support, but also need the support of all sectors of society and the masses. Only in this way, wild animal protection under the perspective of biodiversity protection can be done well; criminal law of wild animal protection is increased; wild animal diversity can be protected; social development can be promoted.

\section{Acknowledgments}

This paper is staged research result of scientific and technical research project of colleges in Inner Mongolia Autonomous Region Construction of Ecological Criminal Law - based on ecological safety protection in Inner Mongolia. Project No.: NJSY14194

\section{References}

[1] Wu Xianping, Criminal protection of wild animal resources under the perspective of biodiversity protection. Guangxi Social Sciences, 2011(9):72-76 
[2] Wu Xianping, Perfection of criminal legislation about animal resource protection under the perspective of comparison method. Journal of Central South University of Forestry \& Technology (Social Sciences), 2012,6(2):119-123

[3] Zhang Qinglang, Criminal protection of biodiversity. Southwestern University of Finance and Economics, 2010:10

[4] Ma Zhangming, Criminal protection of wild animal resources and perfection of legislation. Hebei Law Science, 2011,27(2):136-141

[5] Tian Zhaoshu, On criminal protection of rare and endangered wild animal resources. collected papers of 2010 annual meeting and nationwide environment and resources law seminar, Environment and Resources Law Research Society of China Law Society. 2010:512-517

[6] Wu Dandan, Introspection of protection of wild animals by China' criminal law based on hunting macaques in Jiangxi. Youthful Days, 2013(12):385

[7] Zou Chong, On range of protected animals - from perspective of ecological interest independence. Collected papers of nationwide environment and resources law seminar.2010:789-792.

[8] Liu Xiao, Study on legal system of wild animal protection. Chongqing University, 2010:11

[9] Feng Fangxue, Analysis of criminal protection of China's animal resources. Northern Economy and Trade, 2014(1):58-59 